\title{
Does Academic Performance Affect the Perceived Value of Mentorship, and Mentor's Influence on Student's Satisfaction? A Cross Sectional Study
}

\author{
Nasser A.N. Alzerwi ${ }^{1}$ \\ ${ }^{1}$ Department of Surgery, College of Medicine, Majmaah University, Al Majmaah, Saudi Arabia.
}

\section{ABSTRACT}

\section{BACKGROUND}

An effective mentorship can greatly help medical students in achieving personal and professional success, and satisfaction. Mentorship efforts are therefore gaining increasing importance in medical education. It is important to make a realistic appraisal of factors that can affect the outcome of mentorship exercise, so that specific improvement in mentorship strategy can be made. Academic performance correlates with students' ability to handle learning stress, and their professional and personal competence. This study aims at identifying the perceived value of mentorship in medical students.

\section{METHODS}

A cross-sectional survey was conducted among graduate medical students at the College of Medicine, Majmaah University, in October 2019. The mentees completed an anonymous questionnaire about the perceived quality of the mentorship. Academic performance was evaluated from Garde Point Average (GPA), whether the student has repeated one or more years in the college, and the number of academic papers published by the student. Kruskal-Wallis test was used to determine significant differences among groups. Two-tailed p-value was used to evaluate the statistical significance.

\section{RESULTS}

The questionnaire was sent to 337 mentees. The response rate was $67.7 \%$ and the average age of mentees was $21.9 \pm 1.4$ years. 276 (98\%) mentees were unmarried and 171 (61 \%) were men. 78 (27.7\%) mentees had a GPA of 4.5 - 5.76 (27.0\%) mentees repeated one or more years in the college. 214 (75.9\%) mentees did not have any publication. More men than women had one or more published papers (men $29.2 \%$ vs women $15.2 \%, p=0.04$ ), The median score of Mentorship Relationship Structure (MRS) for the GPA 2 - 2.5 was 8 (IQR = 15) and it increased to 25 (IQR = $12.2)$ in the group with GPA $4.5-5(\mathrm{p}=0.004)$. On MRS, there was no effect of repeating a year in college or the number of papers published (both, $p>0.05$ ).

\section{CONCLUSIONS}

The mentees with extremely low and high GPA can have different perceived quality of the mentorship. The mentorship exercise should be customized to address the specific needs and motivational status of mentees with low and high GPA.

\section{KEY WORDS}

Mentorship, Medical Education, Academic Performance, Mentorship Behaviour Scale
Corresponding Author: Dr. Nasser A. N. Alzerwi, Assistant Professor, Department of Surgery, College of Medicine, Al Majmaah-11952, Saudi Arabia.

E-mail:n.alzerwi@mu.edu.sa

DOI: $10.14260 / \mathrm{jemds} / 2020 / 589$

How to Cite This Article:

Alzerwi NAN. Does academic performance affect the perceived value of mentorship and mentors influence on student's satisfaction? a cross sectional study. J Evolution Med Dent Sci 2020;9(37):27102716, DOI: 10.14260/jemds/2020/589

Submission 26-05-2020,

Peer Review 07-08-2020,

Acceptance 13-08-2020,

Published 14-09-2020.

Copyright (c) 2020 JEMDS. This is an open access article distributed under Creative Commons Attribution License [Attribution 4.0 International (CC BY 4.0)] 


\section{BACKGROUND}

A large number of medical students experience psychological disturbance and lack of professional and personal guidance during their stay in the graduate school.1-3 A proper mentoring of students can alleviate stress and help students in achieving holistic personal and professional success. Mentoring is a bidirectional exercise wherein an experienced person (mentor) guides another individual (protégée or mentee) in his or her learning or developmental process. It is a mutually receptive relationship demanding a lot of commitment from both mentors and mentees. The mentor is expected to carefully examine and understand the strengths, weaknesses, and career goals of mentees and provide suitable guidance. ${ }^{4,5}$

Medical schools present students a great deal of learning opportunities at the same time it involves intense work demands.6,7 The importance of mentorship is getting increasingly realized and more and more medical colleges are incorporating mentorship in their programs to enrich the overall learning experience of the students. ${ }^{8-10}$ Evaluation of the effectiveness of mentorship is a challenging task, given the associated qualitative factors. Hay et al. conducted a systematic review of the effectiveness of the mentorship program in urology. They there stressed the fact that there is no structured approach for mentorship programs for postgraduate training. ${ }^{11}$ Since one of the major tasks in mentorship is to understand the student's need and provide psychological support to the student, the perception of students about the quality and effectiveness of the mentorship exercise can be an effective barometer for the successful mentorship ${ }^{12}$. Brodeur et al. recently constructed a Mentor Behaviour Scale (MBS) to measure students' perceptions of mentoring behaviour during medical training. ${ }^{13}$ The scale was validated in different medical schools and has been demonstrated to have good internal consistency. ${ }^{14}$ MBS involves four dimensions. The first is related to the feedback, organizing meetings, and mentoring goals and is termed as mentoring relationship structure (MRS). Engagement, autonomy support, and competency support are the other three dimensions of this scale. ${ }^{14}$ Overall, the MBS comprised of 15 questions directed at different aspects of mentor-mentee interactions.

Academic performance of a student is associated with psychological well-being, feeling of satisfaction and ability to cope with stressful situations. ${ }^{15}$ In a very important study, Partido et al. reported a positive correlation between emotional intelligence and academic and clinical performance. 16 In another study, it was reported that academic achievers have a high degree of satisfaction whereas poor achievers require special attention. ${ }^{17}$ Improving the academic performance of students is also one of the objectives of the mentorship. Better academic grades correlate well with better professional and personal success and with the overall quality of learning experience. It has also been recognized that medical students with strong academic performance as defined by their grades are more likely to participate in formal mentoring programs. ${ }^{18}$ The role of academic disparities on the perceived effectiveness of mentorship is not explored much, though it is possible that medical students with extremely different academic performance might have a different perception of mentorship and may need a customized approach.
Herein, efforts are made to understand the impact of academic performance on the perceived quality of the mentorship by medical students. Academic performance was evaluated by GPA, repeat in any year in college, and the number of publications by students. Different dimensions of MBS were analysed with respect to the academic performance of students. The effects of gender, age, and academic year were also analysed. In addition to MBS, a direct question was also used to understand students' impressions of mentorship efforts.

\section{METHODS}

The study was conducted at the College of Medicine, Majmaah University from 30 September 2019 to 30 October 2019. The study protocol was approved by the Unit of medical Ethics of King Fahad Medical City (KFMC) (Log number: 20 - 269E). The KFMC institutional review board determined that the study was exempt from human subject research regulations.

\section{Study Design}

A cross-sectional survey was conducted among medical students. The mentees completed an anonymous questionnaire about the mentoring experience and the perceived influence of the mentor on student's overall satisfaction.

\section{Survey Instrument}

A set of questions regarding the student's perceived value of mentorship and mentors' influence on student's overall satisfaction was used. MBS was used to measure students' perceptions of mentoring behaviours. The scale contains different questions on different dimensions (relationship, engagement, autonomy, and competency) of mentor-manatee interactions. The high internal consistency of the MBS has been tested in the setting of medical schools ${ }^{13,14}$. In this work, Cronbach's Alpha was 0.96, 0.86, 0.7, and 0.88 for MRS, engagement, autonomy support, and competency support respectively, confirming high internal consistency of the MBS in our study group. A question that probes into the quality of mentorship "How much are you satisfied about the quality of mentorship program?" was also used. It was aimed at receiving a direct response from the students on their overall understanding and impression of the quality of mentorship

\section{Study Participants}

Participation in the survey was voluntary and mentees were informed that their responses would remain confidential. Written consent was obtained from all mentees.

\section{Definitions}

A mentor is the academic advisor of a mentee. The mentor is expected to provide advice and counseling for personal and professional development. Mentees are students who receive guidance from mentors. Perception is defined as the evaluation of the merits of mentorship and whether 
mentorship meets the needs and expectations of the individual mentee.

\section{Study Variables}

Data pertaining to age, sex, location, marital status, and academic year was extracted for all mentees. Academic performance was gauged on three parameters independently. These parameters were (i) Grade Point Average (GPA) (ii) whether the mentee has repeated one or more years in the college (iii) number of papers published by the mentee.

\section{Statistical Methods}

A descriptive analysis was performed on the extracted data. Variables were presented as numbers and frequency and percentages and mean (with SD) and median (with interquartile range), $95 \% \mathrm{CI}$ for continuous variables. Statistical analysis was conducted with GNU PSPP statistical software (https://www.gnu.org/software/pspp/) and Excel (Microsoft, Redmond, WA). The Chi-square test was used to compare general characteristics. Kruskal-Wallis test was used to determine significant differences among groups. Two-tailed $\mathrm{p}$-value was used to evaluate the statistical significance and the data with a p-value greater than 0.5 was considered significant.

\section{RESULTS}

\section{Demographics}

The questionnaire was sent to 337 mentees. 282 mentees participated in the study (response rate of $67.7 \%$ ). About 61 $\%$ of the respondents were men. One $(0.35 \%)$ of the mentee was less than 18 years old and 7 (2.5\%) of the mentees were 26 years old. The average age was $21.9 \pm 1.4$ years and around $98 \%$ of the mentees were unmarried. $65 \%$ of the mentees were from outside of Majmaah. Mentees were divided into six academic years the first year (pre-academic year) represented by only $3.9 \%$ and the highest number of mentees (23.8\%) were from the third year (2nd basic sciences preclinical year) (Table 1).

\section{Academic Performance}

Academic performance was evaluated from GPA, whether the mentee has repeated one or more years in the college and the number of academic papers published by the mentee. GPA was stratified into 7 groups starting from the lowest $<2$ to the highest 4.5 to 5 . Twenty-eight percent $(n=78)$ of the mentees had the highest grade and only one mentee $(0.35 \%)$ had a grade less than 2. Overall, $70 \%$ of the mentees had a GPA of more than 3.5. Around twenty-seven percent $(n=76)$ of mentees reported that they have repeated one or more years in the college. Among the 76 mentees who had repeated the academic year, $49(17.4 \%)$ repeated one year and two $(0.7 \%)$ repeated 4 years. $75.9 \%$ of mentees did not have any publication. 42 (15.2\%) mentees had one publication and 4 mentees (1.4\%) had more than five publications (Table 2).

\section{Survey Characteristics}

The first 8 questions which reflect the MRS had a median of 23 $(I Q R=14)$. The mean score of specific questions under MRS ranged from 2.57 to 2.72 . The next three questions which represent engagement have a median of $6(\mathrm{IQR}=3)$ and the mean of individual questions ranged from 2.48 to 2.72 . In autonomy support, the median value was $7(\mathrm{IQR}=2)$. The two questions in this group "Often, my mentor makes decisions for me" and "When meeting, my mentor talks more than I do" had a mean score of 3.19 and 3.6 respectively. The competency support group had three questions and a median cumulative score of $9(\mathrm{IQR}=5)$. The mean score values ranged from 2.62 to 2.76 (Table 3, Figure 1).

The survey also included a direct question "How much are you satisfied with the quality of mentorship program?". $28.01 \%$ of mentees responded they were Totally Unsatisfied, 16.31\% mentioned Mostly Unsatisfied, $36.5 \%$ mentioned Somewhat Satisfied and $14.89 \%$ and $4.26 \%$ responded as Mostly Satisfied and Totally Satisfied respectively. The mean score for this question was $2.51 \pm 1.17$ (95\% CI 2.37 - 2.65) and the median was $3(\mathrm{IQR}=2)$.

\section{Effect of Sex on Academic Performance}

There was no significant difference in GPA and repeating a college year. However, more men than women had one or more published papers (men $29.2 \%$ vs women $15.2 \%$, $\mathrm{p}=0.04)$.

\section{Effect of Sex on Mentorship Perception}

There was no significant effect between men and women mentees in terms of MRS ( $p=0.74)$, Engagement ( $p=0.628)$, and Competency support $(p=0.87)$. In autonomy support the difference was statistically significant $(p=0.006)$. In response to "How much are you satisfied with the quality of the mentorship program?", $28.07 \%$ of men and $27.93 \%$ of women responded as Totally Unsatisfied. Totally satisfied was the response of $5.26 \%$ of men and $2.7 \%$ of women. The difference was not statistically significant $(\mathrm{p}=0.15)$.

\begin{tabular}{|c|c|c|}
\hline Variable & $\begin{array}{c}\text { Number of Medical } \\
\text { Mentees (n) }\end{array}$ & (\%) \\
\hline \multicolumn{3}{|c|}{ GPA (grade points average) } \\
\hline$<2$ & 1 & 0.35 \\
\hline $2-2.5$ & 7 & 2.48 \\
\hline $2.5-3$ & 24 & 8.51 \\
\hline 3-3.5 & 50 & 17.73 \\
\hline $3.5-4$ & 70 & 24.82 \\
\hline $4-4.5$ & 52 & 18.44 \\
\hline $4.5-5$ & 78 & 27.66 \\
\hline \multicolumn{3}{|c|}{ Have you repeated any year in college } \\
\hline Yes & & $76(26.95)$ \\
\hline No & & $206(73.05)$ \\
\hline \multicolumn{3}{|c|}{ If you have repeated a year or more, please specify how many } \\
\hline $0^{*}$ & 209 & 74.11 \\
\hline 1 & 49 & 17.38 \\
\hline 2 & 19 & 6.74 \\
\hline 3 & 3 & 1.06 \\
\hline 4 & 2 & 0.71 \\
\hline \multicolumn{3}{|c|}{ Papers published by ( $\mathrm{n}=\mathbf{2 8 2}$ ) students } \\
\hline 0 & 214 & 75.89 \\
\hline 1 & 43 & 15.25 \\
\hline 2 & 8 & 2.84 \\
\hline 3 & 6 & 2.13 \\
\hline 4 & 4 & 1.42 \\
\hline 5 & 3 & 1.06 \\
\hline$>5$ & 4 & 1.42 \\
\hline \multicolumn{3}{|c|}{ Table 1. Academic Performance of $(n=282)$ Mentees } \\
\hline
\end{tabular}




\begin{tabular}{|c|c|c|c|}
\hline $\begin{array}{c}\text { MBS } \\
\text { Domain }\end{array}$ & $\begin{array}{l}\text { Median } \\
\text { (IQR) }\end{array}$ & Variable/Question & Mean \pm SD \\
\hline \multirow{9}{*}{$\begin{array}{l}\text { Mentoring } \\
\text { relationship } \\
\text { structure }\end{array}$} & $23(14)$ & $\begin{array}{l}\text { My mentor gives me useful advice when I tell } \\
\text { him my needs, my worries, and my } \\
\text { difficulties. }\end{array}$ & $2.62 \pm 1.25$ \\
\hline & & $\begin{array}{l}\text { My mentor likes to give me constructive } \\
\text { advice on what I initiate. }\end{array}$ & $2.65 \pm 1.26$ \\
\hline & & $\begin{array}{l}\text { My mentor gives me information to help me } \\
\text { in my actions and in solving my problems }\end{array}$ & $2.65 \pm 1.32$ \\
\hline & & $\begin{array}{l}\text { My mentor and I are working towards } \\
\text { mutually agreed upon goals. }\end{array}$ & $2.62 \pm 1.31$ \\
\hline & & $\begin{array}{l}\text { We have established a good understanding } \\
\text { of the type of changes that would be good for } \\
\text { me. }\end{array}$ & $2.57 \pm 1.3$ \\
\hline & & $\begin{array}{l}\text { My mentor and I agree about the things I will } \\
\text { need to do to help improve my situation. }\end{array}$ & $2.58 \pm 1.28$ \\
\hline & & $\begin{array}{l}\text { We agree on what is important for me to } \\
\text { work on. }\end{array}$ & $2.72 \pm 1.35$ \\
\hline & & $\begin{array}{l}\text { I believe that the way we are working on my } \\
\text { situation is correct. }\end{array}$ & $2.6 \pm 1.26$ \\
\hline & $6(3)$ & $\begin{array}{l}\text { My mentor understands my needs, my } \\
\text { worries, and my problems }\end{array}$ & $2.48 \pm 1.22$ \\
\hline Engagement & & $\begin{array}{c}\text { My mentor listens attentively to the needs, } \\
\text { worries, and achievements that I share with } \\
\text { him. }\end{array}$ & $2.72 \pm 1.27$ \\
\hline \multirow{3}{*}{$\begin{array}{l}\text { Autonomy } \\
\text { support }\end{array}$} & $7(2)$ & $\begin{array}{l}\text { When meeting, my mentor talks more than I } \\
\text { do }\end{array}$ & $3.19 \pm 1$ \\
\hline & & Often, my mentor makes decisions for me. & $3.6 \pm 1.33$ \\
\hline & $9(5)$ & $\begin{array}{l}\text { My mentor values me even after I experience } \\
\text { failures. }\end{array}$ & $2.64 \pm 1.3$ \\
\hline \multirow{2}{*}{$\begin{array}{l}\text { Competency } \\
\text { support }\end{array}$} & & My mentor often tells me what I do well. & $2.62 \pm 1.22$ \\
\hline & & $\begin{array}{l}\text { My mentor congratulates me when I do } \\
\text { something right. }\end{array}$ & $2.76 \pm 1.31$ \\
\hline
\end{tabular}

\begin{tabular}{|c|c|c|c|c|c|}
\hline GPA & \multicolumn{2}{|c|}{ MRS } & \multicolumn{2}{|c|}{ Engagement Autonomy } & Competence \\
\hline \multirow{3}{*}{$2-2.5$} & Mean & $14.43 \pm 8.04$ & $3.71 \pm 4$ & $7.29 \pm 2.21$ & $6 \pm 2.65$ \\
\hline & $95 \%$ & $6.99-21.86$ & $1.74-5.69$ & $5.24-9.33$ & $3.55-8.45$ \\
\hline & Median (IQR) & $8(15)$ & $2(4)$ & $7(4)$ & $5(6)$ \\
\hline \multirow{3}{*}{$2.5-3$} & Mean & $19.13 \pm 9.35$ & $4.5 \pm 1.96$ & $6.13 \pm 2.76$ & $7.33 \pm 4.18$ \\
\hline & $95 \%$ & $15.18-23.07$ & $3.67-5.33$ & $4.96-7.29$ & $5.57-9.1$ \\
\hline & Median (IQR) & $20(17)$ & $5(4)$ & $6(4.75)$ & $6.5(9)$ \\
\hline \multirow{4}{*}{$3-3.5$} & Mean & $19.14 \pm 9.13$ & $4.72 \pm 2.4$ & $6.58 \pm 2.48$ & $7.48 \pm 3.75$ \\
\hline & $95 \%$ & $16.54-21.74$ & $4.04-5.4$ & $5.88-7.28$ & $6.41-8.55$ \\
\hline & Median (IQR) & $18(16)$ & $4(4)$ & $7(3)$ & 7 (7) \\
\hline & Mean & $20.2 \pm 9.01$ & $5.23 \pm 2.19$ & $7 \pm 2.1$ & $8 \pm 3.09$ \\
\hline \multirow[t]{2}{*}{$3.5-4$} & $95 \%$ & $18.05-22.35$ & $4.71-5.75$ & $6.5-7.5$ & $7.26-8.74$ \\
\hline & Median (IQR) & $21.5(15)$ & $6(2)$ & $2(2)$ & $9(12)$ \\
\hline \multirow{4}{*}{$4-4.5$} & Mean & $20.67 \pm 8.82$ & $4.9 \pm 2.39$ & $7.13 \pm 2.13$ & 7.88 \\
\hline & $95 \%$ & $18.22-23.13$ & $4.24-5.57$ & $6.54-7.73$ & $6.93-8.84$ \\
\hline & Median (IQR) & $20.5(13.75)$ & $5.5(4)$ & $7.5(3)$ & $9(5)$ \\
\hline & Mean & $24.28 \pm 8.83$ & $6.01 \pm 2.33$ & $6.65 \pm 2.19$ & $8.85 \pm 3.28$ \\
\hline \multirow{2}{*}{$4.5-5$} & $95 \%$ & $22.29-26.27$ & $5.49-6.54$ & $6.16-7.15$ & $8.11-9.59$ \\
\hline & Median (IQR) & $25(12.25)$ & $6(3.25)$ & $6.73(2.25)$ & $9(4.25)$ \\
\hline \multicolumn{2}{|c|}{$\begin{array}{l}\text { P-Value Kruskal-Wallis } \\
\text { test } \\
\text { *statistically significant } \\
\mathrm{P}<0.05\end{array}$} & $0.004^{*}$ & $0.007^{*}$ & 0.693 & 0.174 \\
\hline \multicolumn{6}{|c|}{ Table 3. GPA and Scores in Different Domains of MBS } \\
\hline
\end{tabular}

\begin{tabular}{|c|c|c|c|c|c|}
\hline Papers & & MRS & Engagement & Autonomy & Competence \\
\hline \multirow{4}{*}{0} & Mean & $21.64 \pm 9.01$ & $5.32 \pm 2.27$ & $6.77 \pm 2.24$ & $8.19 \pm 3.34$ \\
\hline & $95 \%$ & $20.43-22.86$ & $5.01-5.62$ & $6.47-7.07$ & $7.74-8.64$ \\
\hline & $\begin{array}{l}\text { Median } \\
\text { (IQR) }\end{array}$ & $24(12.25)$ & $6(3)$ & $7(2.25)$ & $9(4)$ \\
\hline & Mean & $17.77(8.82)$ & $4.53(2.42)$ & $6.81(2.49)$ & $7(3.63)$ \\
\hline \multirow{2}{*}{1} & $95 \%$ & $15.05-20.48$ & $3.79-5.28$ & $6.05-7.58$ & $5.88-8.12$ \\
\hline & $\begin{array}{c}\text { Median } \\
\text { (IQR) }\end{array}$ & $17(16)$ & $4(4)$ & 7 (3) & $6(6)$ \\
\hline \multirow{3}{*}{2} & Mean & $24.88 \pm 11.84$ & $6.25 \pm 2.92$ & $7.63 \pm 1.92$ & $9 \pm 4.47$ \\
\hline & $95 \%$ & $14.98-34.77$ & $3.81-8.69$ & $6.02-9.23$ & $5.26-12.74$ \\
\hline & $\begin{array}{l}\text { Median } \\
(\mathrm{IQR})\end{array}$ & $31(22.25)$ & $7(5)$ & $8(2.75)$ & $10.5(8.25)$ \\
\hline \multirow{3}{*}{3} & Mean & $18 \pm 10.49$ & $5 \pm 2.83$ & $6.67 \pm 2.8$ & $7.5 \pm 4.18$ \\
\hline & $95 \%$ & $6.99-29.01$ & $2.03-7.97$ & $3.72-9.61$ & $3.11-11.89$ \\
\hline & $\begin{array}{l}\text { Median } \\
\text { (IQR) }\end{array}$ & 16.5 (19.25) & $5(5.5)$ & $7.5(4.25)$ & $7.5(8.5)$ \\
\hline \multirow{3}{*}{4} & Mean & $13.5 \pm 7.14$ & $3.75 \pm 1.71$ & $7.25 \pm 1.89$ & $6 \pm 3.46$ \\
\hline & $95 \%$ & $2.14-24.86$ & $1.03-6.47$ & $4.24-10.26$ & $0.49-11.51$ \\
\hline & $\begin{array}{l}\text { Median } \\
\text { (IQR) }\end{array}$ & $11(12)$ & $3.5(3.25)$ & $6.5(3.25)$ & $6(6)$ \\
\hline \multirow{3}{*}{5} & Mean & $18.67 \pm 5.51$ & $3.33 \pm 1.15$ & $5.67 \pm 2.89$ & $9.67 \pm 4.04$ \\
\hline & $95 \%$ & $4.99-32.35$ & $0.46-6.2$ & $-1.5-12.84$ & $-0.37-19.71$ \\
\hline & $\begin{array}{l}\text { Median } \\
\text { (IQR) }\end{array}$ & $16(10)$ & $4(2)$ & $4(5)$ & $12(7)$ \\
\hline \multicolumn{2}{|c|}{$\begin{array}{c}\text { P value } \\
\text { Kruskal-Wallis test }\end{array}$} & 0.481 & 0.653 & 0.58 & 0.84 \\
\hline & Table & $\begin{array}{l}\text { umber of } \\
\text { cores in } D\end{array}$ & $\begin{array}{l}\text { ers Publis } \\
\text { rent Domo }\end{array}$ & $\begin{array}{l}\text { by a Men } \\
\text { of } M B S\end{array}$ & and \\
\hline
\end{tabular}

\begin{tabular}{|c|c|c|c|c|c|c|}
\hline Academic & $\mathbf{n}$ & $\begin{array}{l}\text { Totally } \\
\text { Un- }\end{array}$ & $\begin{array}{l}\text { Mostly } \\
\text { un- }\end{array}$ & $\begin{array}{l}\text { Some } \\
\text { what }\end{array}$ & Mostly & Totally \\
\hline Year & (\%) & satisfied & satisfied & satisfied & satisfied & Satisfied \\
\hline & & $(\%)$ & $(\%)$ & $(\%)$ & & \\
\hline $\begin{array}{c}\text { 1st year } \\
\text { (Pre-medical year) }\end{array}$ & $\begin{array}{c}11 \\
(3.9)\end{array}$ & $0.00 \%$ & $9.09 \%$ & $18.18 \%$ & $63.64 \%$ & $9.09 \%$ \\
\hline $\begin{array}{l}\text { 2nd year ( } 1^{\text {st }} \\
\text { Basic sciences } \\
\text { preclinical year) }\end{array}$ & $\begin{array}{c}53 \\
(18.79)\end{array}$ & $11.32 \%$ & $5.66 \%$ & $47.17 \%$ & $26.42 \%$ & $9.43 \%$ \\
\hline $\begin{array}{l}\text { 3rd year ( } 2^{\text {nd }} \\
\text { basic sciences } \\
\text { preclinical year })\end{array}$ & $\begin{array}{c}67 \\
(23.76)\end{array}$ & $25.37 \%$ & $19.40 \%$ & $41.79 \%$ & $10.45 \%$ & $2.99 \%$ \\
\hline $\begin{array}{l}4 \text { th year }(1 \text { st } \\
\text { Clinical year })\end{array}$ & $\begin{array}{c}41 \\
(14.54)\end{array}$ & $24.39 \%$ & $24.39 \%$ & $34.15 \%$ & $12.20 \%$ & $4.88 \%$ \\
\hline $\begin{array}{l}\text { 5th year }\left(2^{\text {nd }}\right. \\
\text { Clinical year })\end{array}$ & $\begin{array}{c}39 \\
(13.83)\end{array}$ & $25.64 \%$ & $17.95 \%$ & $43.59 \%$ & $12.82 \%$ & $0.00 \%$ \\
\hline $\begin{array}{l}\text { 6th year ( } 3^{\text {rd }} \\
\text { Clinical year })\end{array}$ & $\begin{array}{c}35 \\
(12.41)\end{array}$ & $51.43 \%$ & $14.29 \%$ & $25.71 \%$ & $2.86 \%$ & $5.71 \%$ \\
\hline Internship & $\begin{array}{c}36 \\
(12.77)\end{array}$ & $50.00 \%$ & $19.44 \%$ & $22.22 \%$ & $8.33 \%$ & $0.00 \%$ \\
\hline \multicolumn{7}{|c|}{$\mathrm{P}$ value $=0.002$. chi square test } \\
\hline \multicolumn{7}{|c|}{$\begin{array}{c}\text { Table 5. Response of the Mentees in Different Academic } \\
\text { Years to the Direct Question }\end{array}$} \\
\hline
\end{tabular}

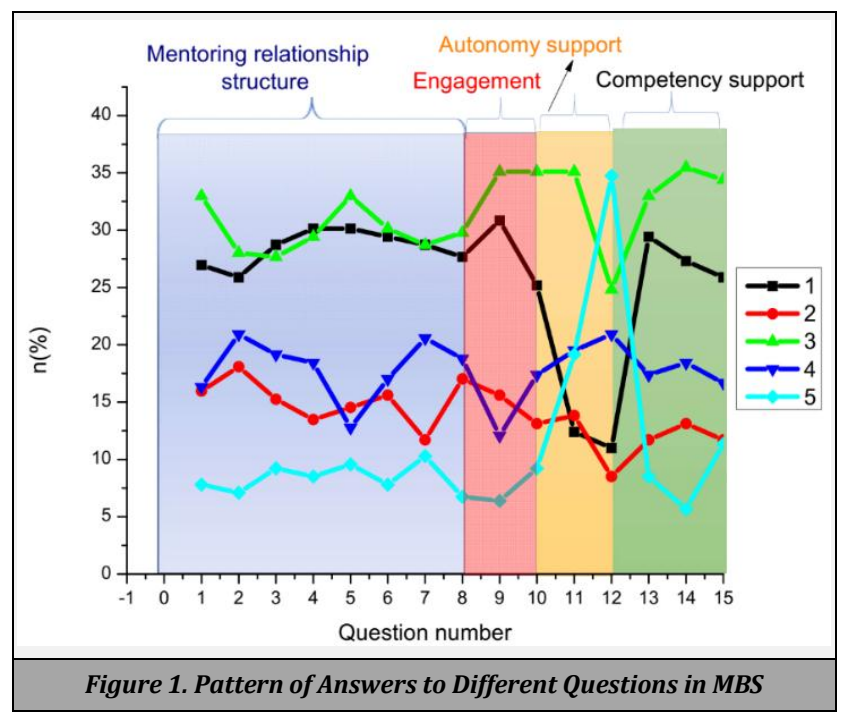

Effect of Academic Performance on Mentorship Perception

The median MRS, Engagement, Autonomy support, and Competency support scores for different GPA groups are presented in table 4. The median (IQR) of MRS value for GPA 2 - 2.5 group was 8 (IQR 15) and it increased to 25 (IQR 12.25) in the GPA 4.5-5 group ( $\mathrm{p}=0.004)$. In terms of engagement, the median (IQR) for GPA $2-2.5$ group was 2 (4) and it increased to 6 (3.25) in GPA 4.5 - 5 group ( $\mathrm{p}=0.007$ ). Autonomy support median score for GPA 2 - 2.5 group was 7 (4) and it decreased to 6.73 (2.25) for GPA $4.5-5$ group ( $p=0.693$ ). In terms of Competency support, the median score for GPA $2-2.5$ group was 5 (6) and it increased to 9 (4.25) for GPA 4.5 - 5 group (p $=0.175)$.

To the direct question, more students responded "totally unsatisfied" in GPA 2 - 2.5 group than in GPA 4.5 - 5 (42.9\% vs $16.7 \%$ ) and the difference among GPA groups was statistically significant ( $p=0.001$, Table 5). In response to the question "Have you repeated any year in college" the mentees who responded 'Yes', the median MRS score was 21.5 (12.5) and the score was 22 (12) for mentees who responded 'No' ( $p=0.213$ ). For autonomy support, the median score was 7 (2) and 6.5 (3) respectively for 'Yes' and 'No' responses ( $\mathrm{p}=0.199)$. For Engagement, the mean score was 6 (4) and 5 (3.75) for 'Yes' and 'No' responses respectively $(\mathrm{p}=0.217)$, and for Competence support, the median score was 9 (5) and 9 (4.75) for 'Yes' and 'No' responses respectively $(\mathrm{p}=0.7)$. 
To the direct question, an almost similar fraction of mentees responded "totally unsatisfied" in the 'Yes' group and 'No' groups. There was no statically significant difference between these two groups ( $\mathrm{p}=0.597)$. The students who have repeated any year has a lower GPA than those who didn't $(\mathrm{p}<0,05)$

The effect of the number of published papers was also analysed. There was no significant difference in any of the domain of MBS (all $p>0.05$ ). There was no significant difference or an increasing or decreasing trend with an increase in the number of publications. The maximum value on all parameters was found to be in the mentees with two publications. No significant difference was observed among mentees with different number of publications in response to the direct question $(\mathrm{p}=0.29)$.

In different academic years, the responses of mentees in the domain MRS, Engagement, and Competence support were statistically different (all $\mathrm{p}<0.05$ ). In response to the direct question, almost $50 \%$ of mentees in Internship and 6th year (3rd Clinical year) responded "Unsatisfied" and the $40 \%$ mentees in 2nd year (1 $1^{\text {st }}$ Basic sciences preclinical year) and 3rd year $\left(2^{\text {nd }}\right.$ basic sciences preclinical year) responded somewhat satisfied $(\mathrm{p}<0.05)$.

\section{DISCUSSION}

Mentorship plays a critical role in the learning and professional development of medical students. Mentoring programs are therefore gaining increasing importance in undergraduate education. In this work, we have demonstrated that certain parameters of academic performance can affect the perceived effectiveness of mentorship among mentees though many other parameters such as gender do not have a significant influence. Furthermore, this effect is not consistent among all dimensions of mentorship.

In this study, the mentee with an extremely high and extremely low GPA had a very different perception of mentorship effectiveness. If different dimensions of mentorship are considered, the mean MRS score in mentees with a low GPA (2 - 2.5) was considerably less than that observed in mentees with a high GPA group (4.5 - 5). The intermediate GPA range has an MRS score of about 19. MRS measures specific behaviours regarding giving feedback, organizing meetings, and mentoring goals and has been reported to have good internal consistency ( $\alpha=0.96) .{ }^{13,14}$ The internal consistency in this study was in close agreement with the reported values. The score in the high GPA group was close to 24 , therefore can be considered moderate ${ }^{14}$. The mentees with the highest GPA had a better perception of the mentor's supportive behaviour. Notably, this fact is observed only in groups with extreme GPA performance. To the best of our knowledge, such factors are not elucidated in previous research. One possible explanation could be the fact that the mentees with a high GPA had a more active engagement with mentors. If scores in engagement domains are considered, this hypothesis is verified as the highest GPA and lowest GPA groups had a statistically significant difference. Notably, engagement defines rapport, bonding, quality of time, and listening skills. In the competency support domain also, the higher GPA group had a higher score. The observed effect of
GPA, therefore, can be attributed to the high capability of meritorious mentees in dealing with challenges during learning and their likelihood of having more active engagements with the mentor. ${ }^{19}$ Autonomy is a reflection of mentor support and the assistance in mentees' decisionmaking processes; whereas, competence measures the psychological support for mentees' academic and nonacademic performance. This finding further indicates mentees with a high GPA had a higher perceived quality of the mentoring relationship, though such differences are not prominent in the domains related to the mentors' assistance in decision making process. ${ }^{20-22}$

There was no effect of repeating a college year on mentees' perceptions of the effectiveness of mentorship in any of the MBS dimensions. It might have been anticipated that these two groups will have different MRS and engagement; however, the results suggest that when it comes to the utilization of the mentorship these two groups have no statistically significant difference. In pursuits to understand the factors associated with poor academic performance and dropouts, O'Neill et al concluded that struggling academically in medical school may be strongly associated with dropout but there no specific pattern of demographic variables was particularly important in relation to dropout ${ }^{23}$. Dendle et al. analysed the effect of psychological distress and academic performance and reported a poor correlation was noted between psychological distress and academic performance. ${ }^{24}$ Such factors can also be attributed to the observed behaviour of repeating a college year on the perceived quality of mentorship. The result essentially indicates that the response of students who have repeated a college year is not necessarily similar to those students who have lower academic grades 25 . One reason could be that the students repeating a year have realized the importance of good learning practices and have improved on their grades. However, when the data was analysed, it was found that students who have repeated a year have considerably lower academic grades. This may imply that the poor academic performance of this group might not be because of a lack of motivation and psychological barriers. However, this different perception of the mentorship behaviour of this subgroup needs further probing in this area, perhaps dedicated research on the motivational and mentorship needs of the students who have repeated a college year. Based on this work, only a limited conclusion can be drawn, that is both groups in our study have a statistically similar perception of the quality of mentorship.

The number of papers published by mentees was also analysed in this study. It was found that about $17 \%$ of mentees had one or more publications. There was a difference between the paper published by men and women groups, with men having a significantly higher number of publications. These results are in line with other studies concluding women publish fewer articles compared to men. ${ }^{26}$ However, when mentorship values are compared, there was no statistically significant difference in any of the dimensions of MBS. In previous studies also, there were no significant relationships between gender and the MRS were found ${ }^{14}$. Furthermore, in terms of the number of publications, there was no difference in the mentorship perception between the mentees who had publications or those who didn't. It was anticipated that the mentees with a greater number of publications might have a better quality of mentorship structure ${ }^{27}$; however, the results 
do not support that. One of the reasons could be that publications may involve a more specified interaction with a faculty member who may not necessarily be a mentor. The faculty who helped the mentee in conducting research and other activities related to publications might have different goals and functions than the mentor assigned as a part of the mentorship exercise. More studies however needed to fully understand and validate this observation.

Another important finding was the fact that the mentoring relationships were perceived differently by mentees in different years of study. This indicates that different phases of medical training influence perceptions of supportive mentoring behaviours. Interestingly, medical mentees who were in the first year valued mentoring relationships more highly. This might be due to their more dependence on mentors for gaining information regarding different aspects of the medical career. In year 3 to year 5 , the majority of the response was "somewhat"; however, the response was "totally Unsatisfied" in $50 \%$ of the mentees in year six and internship. These results suggest the mentees' expectations and needs might vary in different academic years. Internship, in particular, poses a more psychologically demanding and stressful situation to students. ${ }^{28}$ Mohammad et al. reported that mentoring relationships more highly valued in the transition phase between years $2-4 .{ }^{14}$ Maybe this difference is because in their study they have excluded the students in the initial years. Based on the results of this study, the necessary changes should be made in the mentoring exercise considering the specific needs of mentees in the particular academic year, especially for mentees in the early and the final year or in the internship.

Although the present study was confined to a single medical school, the practical implications may apply to other medical schools as well. The scores in this study are low except for mentees having the highest GPA. This suggests a scope of more appropriate and rigorous methods of mentor screening, training, and recruitment to provide a better positive mentoring experience for mentees.

This current study had several limitations. It is a singlecenter study therefore generalizations of results should be made with caution. Duration, nature, and frequency of menteementor interactions should also be analyzed, before generalizing the cause and effect relationship based on the results reported in this work. Qualifications of mentors and other personality traits may also affect the perceived quality of mentorship, and need to be analyzed. Furthermore, though in this work only academic year and GPA were found to affect the perception of mentorship effectiveness among students, confounding effects cannot be completely ruled out. However, it may be highlighted here that in the mentorship exercise a uniform protocol for mentorship has been adopted, so a major variation in the nature and frequency of mentee-mentor interactions is not expected in this study.

\section{CONCLUSIONS}

This study investigated whether mentees' academic performance affects the perceived quality of the mentorship in a medical school setting. Results suggest that there is no difference in terms of gender, but academic year significantly affects the mentees' perceived value of mentorship. Mentees with an extreme GPA had a markedly different score of MRS, autonomy support, and competency support but there was no significant difference in terms of engagement. Repeating a year in college was not found to have any effect on the perceived value of mentorship; neither was there any significant effect of the number of publications by mentees. Further efforts are necessary to elucidate finer aspects of supportive mentoring behaviours in medical education. Careful consideration to GPA, the academic year, may need to be given. Mentoring programs, and the duration, frequency, and nature of menteementor interactions should be modified accordingly.

The study protocol was approved by the Unit of medical Ethics of King Fahad Medical City (Log Number: 20 - 269E). The KFMC institutional review board determined that the study was exempt from human subject research regulations. Informed written consent was obtained from all participants before participation.

Financial or Other Competing Interests: None.

\section{REFERENCES}

[1] Guthrie EA, Black D, Shaw CM, et al. Embarking upon a medical career: psychological morbidity in first year medical students. Med Educ 1995;29(5):337-41.

[2] Kassim SS, McGowan Y, McGee H, et al. Prepared to practice? Perception of career preparation and guidance of recent medical graduates at two campuses of a transnational medical school: a cross-sectional study. BMC Medical Education 2016;16(1):56.

[3] Tempski P, Bellodi PL, Paro HBMS, et al. What do medical students think about their quality of life? A qualitative study. BMC Med Educ 2012;12:106.

[4] Haines ST. The Mentor-Protégé relationship. American Journal of Pharmaceutical Education 2003;67(3):458-64.

[5] Choi AMK, Moon JE, Steinecke A, et al. Developing a culture of mentorship to strengthen academic medical centers. Acad Med 2019;94(5):630-3.

[6] Hill MR, Goicochea S, Merlo LJ. In their own words: stressors facing medical students in the millennial generation. Med Educ Online 2018;23(1):1530558.

[7] Ishak W, Nikravesh R, Lederer S, et al. Burnout in medical students: a systematic review. Clin Teach 2013;10(4):242-5.

[8] Buddeberg-Fischer B, Herta KD. Formal mentoring programmes for medical students and doctors -- a review of the Medline literature. Med Teach 2006;28(3):248-57.

[9] Nimmons D, Giny S, Rosenthal J. Medical student mentoring programs: current insights. Adv Med Educ Pract 2019;10:113-23.

[10] Sambunjak D, Straus SE, Marusic A. A systematic review of qualitative research on the meaning and characteristics of mentoring in academic medicine. J Gen Intern Med 2010;25(1):72-8.

[11] Hay D, Khan MS, Van Poppel H, et al. Current status and effectiveness of mentorship programmes in urology: a systematic review. BJU Int 2014;116(3):487-94. 
[12] McLuckie A, Matheson KM, Landers AL, et al. The relationship between psychological distress and perception of emotional support in medical students and residents and implications for educational institutions. Acad Psychiatry 2018;42(1):41-7.

[13] Brodeur P, Larose S, Tarabulsy G, et al. Development and construct validation of the mentor behavior scale. Mentoring \& Tutoring: Partnership in Learning 2015;23(1):54-75.

[14] Mohammad JAM, Rahim AFA, Nor MZA, et al. Supportive mentoring behaviours in a public medical school. International Journal of Mentoring and Coaching in Education 2019;8(2):102-19.

[15] Trucchia SM, Lucchese MS, Enders JE, et al. Relationship between academic performance, psychological wellbeing, and coping strategies in medical students. Rev Fac Cien Med Univ Nac Cordoba 2013;70(3):144-52.

[16] Partido BB, Stafford R. Association between emotional intelligence and academic performance among dental hygiene students. J Dent Educ 2018;82(9):974-9.

[17] Shareef MA, AlAmodi AA, Al-Khateeb AA, et al. The interplay between academic performance and quality of life among preclinical students. BMC Med Educ 2015;15:193.

[18] Dimitriadis K, von der Borch P, Störmann S, et al. Characteristics of mentoring relationships formed by medical students and faculty. Med Educ Online 2012;17(1):17242.

[19] Campbell TA, Campbell DE. Faculty/student mentor program: effects on academic performance and retention. Research in Higher Education 1997;38(6):727-42.
[20] Myall M, Levett-Jones T, Lathlean J. Mentorship in contemporary practice: the experiences of nursing students and practice mentors. J Clin Nurs 2008;17(4):1834-42.

[21] van Schalkwyk GI, Katz RB, Resignato J, et al. Effective research mentorship for residents: meeting the needs of early career physicians. Academic psychiatry: the journal of the American Association of Directors of Psychiatric Residency Training and the Association for Academic Psychiatry 2017;41(3):326-32.

[22] Swendiman RA, Hoffman DI, Bruce AN, et al. Qualities and methods of highly effective surgical educators: a grounded theory model. J Surg Educ 2019;76(5):1293302.

[23] O'Neill LD, Wallstedt B, Eika B, et al. Factors associated with dropout in medical education: a literature review. Med Educ 2011;45(5):440-54.

[24] Dendle C, Baulch J, Pellicano R, et al. Medical student psychological distress and academic performance. Med Teach 2018;40(12):1257-63.

[25] Li J, Thompson R, Shulruf B. Struggling with strugglers: using data from selection tools for early identification of medical students at risk of failure. BMC Med Educ 2019;19(1):415.

[26] Bendels MHK, Muller R, Brueggmann D, et al. Gender disparities in high-quality research revealed by Nature Index journals. PloS One 2018;13(1):e0189136.

[27] Liénard JF, Achakulvisut T, Acuna DE, et al. Intellectual synthesis in mentorship determines success in academic careers. Nat Commun 2018;9(1):4840.

[28] Miranda-Ackerman RC, Barbosa-Camacho FJ, SanderMöller MJ, et al. Burnout syndrome prevalence during internship in public and private hospitals: a survey study in Mexico. Med Educ Online 2019;24(1):1593785. 